\title{
FINITE ELEMENT ANALYSIS OF AN EXCAVATOR BUCKET WITH EMBEDDING RIPPER TEETH
}

\author{
PhD. Aurora POTÎRNICHE

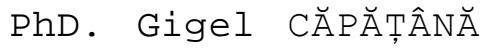 \\ "Dunărea de Jos" University of Galați, \\ Engineering Faculty of Brăila, \\ Research Center for Mechanics of Machines \\ and Technological Equipments
}

\begin{abstract}
This paper deals with the study of a special excavator bucket, namely the Leading Edge bucket, which is a bucket with embedding ripper teeth. This type of equipment has been taken over from the literature, the 3D model has been generated in the Solid Edge assisted design software, then a detail has been chosen from the bucket assembly, namely a tooth, and it has been introduced in a specialized software of finite element analysis, namely Algor, and subjected to an analysis. The goal of the finite element analysis was to observe the state of stresses and deformations that occur in the structure during the digging process, when multidirectional stresses act on the bucket. The results obtained may be used by those skilled in the domain to improve the work performances of such equipment.
\end{abstract}

KEYWORDS: Leading Edge bucket, bucket with ripper teeth, 3D model, specialized software of finite element analysis, state of stresses and deformations

\section{INTRODUCTION}

A single-bucket excavator is a selfpropelled machinery, which can be moved on a road or on an unassembled terrain, provided with wheels or tracks.

The single-bucket excavat or is intended for earth digging and loading. It follows from this definition that the place of the excavator with a single bucket must be in a system of construction machinery which ensures the mechanized execution of a technological process of earthworks.

Regarding the efficient use of hydraulic excavators, there is a wider use of excavators with more work equipment made up of modular elements. The use of these excavat ors for small volumes of different works has the effect of reducing the number of machines involved in the technological process of earthworks and the costs of renting them.

\section{THEORETICAL APPROACHES} Designed to work in areas with severe climates and heavy soils, the Leading Edge can be used for a wide range of applications, such as fossil soils, sandstone, limestone, shale.

The unique design with several teeth attached to the back of the bucket has proven that it can dig faster with this configuration than using a single scarifier tooth. Given some severe excavation conditions, the performance exceeds far the results of working with classic bucket models.

The Leading Edge bucket scarifies and digs in the same time. The back of the bucket executes the scarification by penetrating with the teeth into the ground and the front of the bucket performs the digging operation. The two functions performed at the same time lead t o time and fuel saving, ultimatel $y$ leading to cost savings for the producing company.

The teeth on the back of the bucket are practiced sequentially. There are no two teeth aligned or generated symmetrically, so that the maximum breaking force is applied successively to each tooth. The grooves 
formed by the first teeth allow the back teeth to penetrate into the ground.

During the working process, by extending the cylinder operating the bucket, the full breaking force is always ensured, so that the substrate is plucked through the lifting action of each tooth.

Figure 1 shows a Leading Edge bucket model, taken from the literature during the work process.

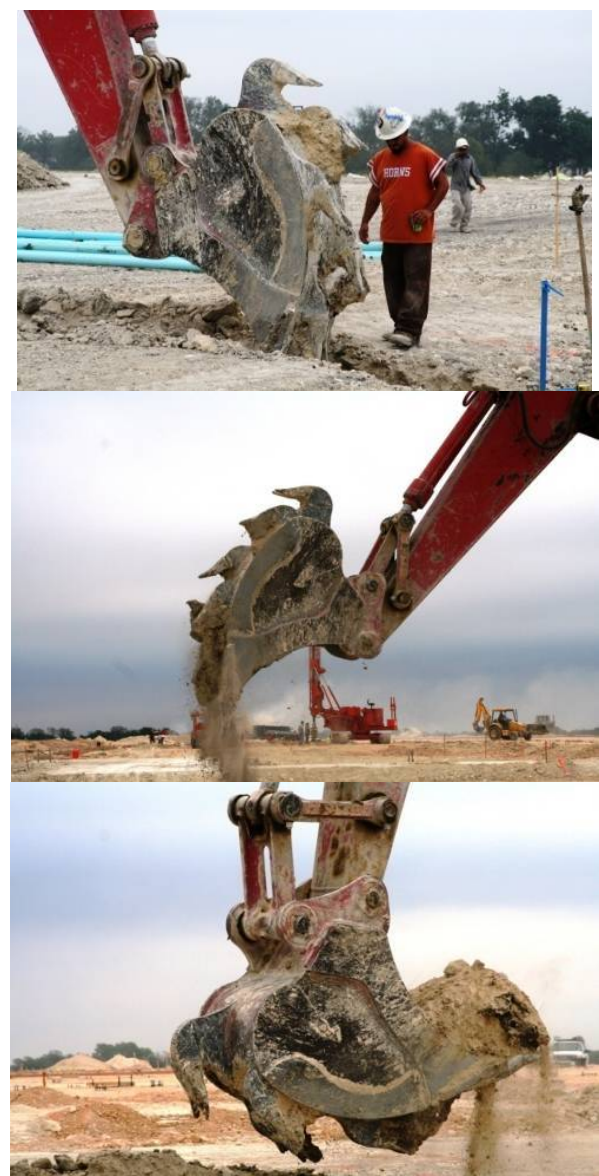

Fig. 1 Presentation of the working process using the Leading Edge bucket

\section{CASE STUDY}

The Leading Edge bucket model presented above was taken from the literature and the 3D model was executed in Solid Edge.

The Solid Edge software approaches all aspects of the design process - 3D design, simulation, manufacturing, design management, collaboration and enables companies to make smarter product-related decisions. This results in the development of qualitative and efficient products. In addition to the mentioned design and simulation capabilities, Solid Edge ST6 provides its users with a great learning and collaboration experience.

The modeling has been done following the steps:

- the sketch of models was made using the SKETCH command for each new operation;

- the PROTRUSION command was used for the generation of the solid model;

- the CUTOUT commands were used to cut and remove some areas of the solid;

- to generate holes the HOLE command was used;

- the parallel planes (PARALEL PLANE) and the coincidental planes (COINCIDENT PLANE) were used to create the sketches needed to generate the model;

- the ROUND and CHAMFER commands were used to complete the model details.

Figure 2 shows the bucket in the final construction version, modeled with Solid Edge ST6.
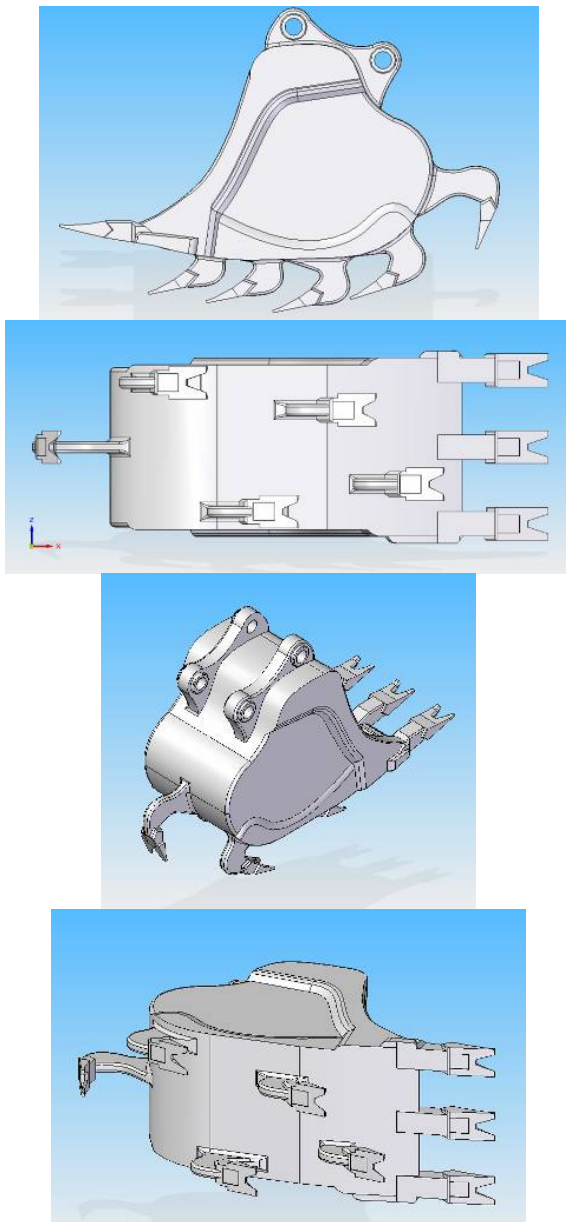

Fig. 2 3D model for Leading Edge bucket

From the bucket assembly was extracted a detail, namely a tooth, which we present in figure 3 . The purpose of extracting the detail 
was to perform a finite element analysis on the tooth of the bucket. The analysis was carried out in a situation in which, during the digging process, there are stresses which occur on several directions on the tooth.

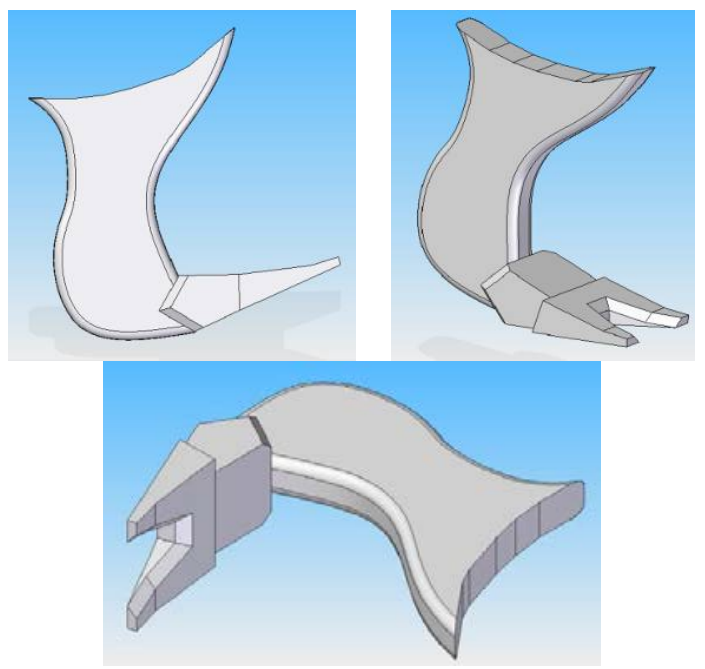

Fig. 3 A detail that represents a tooth of the bucket

One tooth of the bucket was analyzed in afinite element analysis software called ALGOR.

The finite element method, although known for some time, is a direct product of the informational era. The programs developed on the basis of this method have evolved from applications designed solely to assess the stresses and the deformations of the resistance structures to complex program packages designed to approach numerically many types of problems.

The analysis aimed at highlighting the stresses and the deformations that develop in the tooth of the bucket in the considered cases of solicitations.

In a first state, it is considered that a tooth of the bucket penetrates into the ground and, on it, acts frontally a pressure equivalent to the specific resistance to digging, case which corresponds to the actual situation of hitting an obstacle.

The 3D model of the tooth was imported into the Algor software, it was assigned a material (OL 37), a three-dimensional finite element type, suitable for 3D structures (Brick) and automatically meshed by the software.

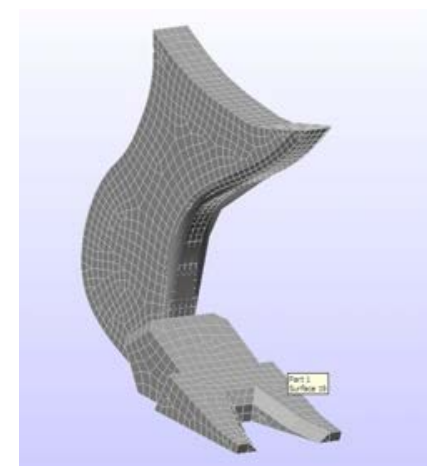

Fig. 4 The discretization of the bucket tooth in Algor

In the next step, the user inserts the support set and the loading set into Algor.

The support is of the embedding type and is made on the surface of the tooth where it is engaged on the bucket.

The loading in the first situation is of pressure type acting frontally on two surfaces of the tooth. The pressure is equivalent to the specific resistance to digging, corresponding to the $\mathrm{IV}^{\text {th }}$ category of hard ground and was taken as value from the tables presented in the literature. In this case, was chosen for pressure the value $0,25 \mathrm{~N} / \mathrm{mm}^{2}$ corresponding to heavy or wet clay or poorly cemented conglomerate.

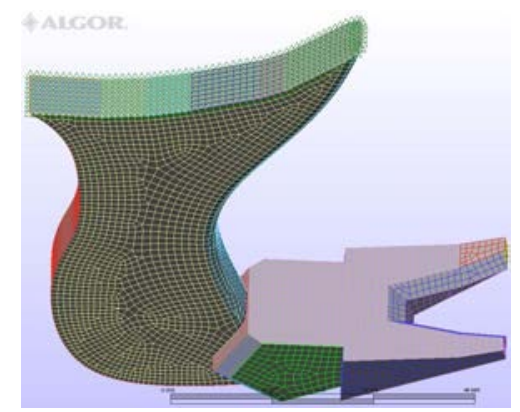

Fig. 5 The defining of the support set in the case of frontal solicitation

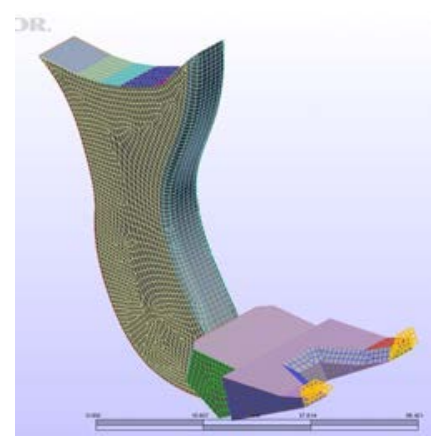

Fig. 6 The defining of the load set in the case of frontal solicitation

From the set of results obtained, it is 
interesting to visualize the stress state that occurs in the tooth and the displacement of its nodes under the action of the proposed solicitation.

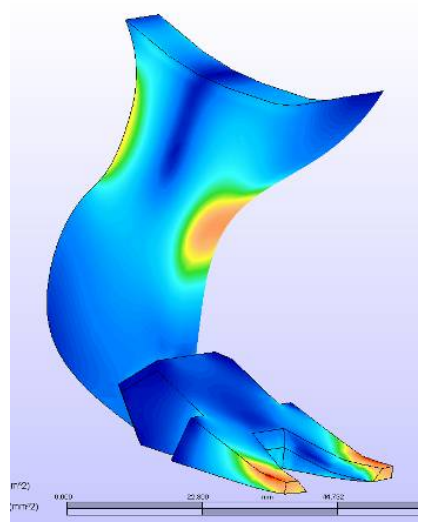

Fig. 7 The viewing of the the stress state in the case of frontal solicitation

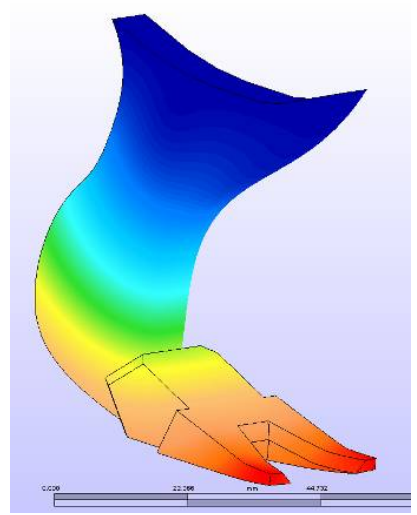

Fig. 8 The viewing of the displacements of the nodes from the tooth in the case of frontal solicitation

In a second state, it is considered that the same tooth of the bucket is in the pile of earth and attempts to remove the full bucket from the heap - the tooth is subject to a pressure given by the specific resistance to digging, but this time in the vertical direction, direction on which the bucket is removed from the earth; this case corresponds to the real situation in which the tooth of the bucket "gets stuck" in an obstacle at the moment of pulling out of the heap.

The support set for the second case study is the same as for the first case, i.e., the embedding in the tooth holding area at the bucket, the working hypotheses being the same.

The loading in the second situation is a pressure that acts vertically on two surfaces of the tooth in the sense of pressing it from top to bottom. The pressure is the same from the previous situation, because the tooth works in the same type of soil.

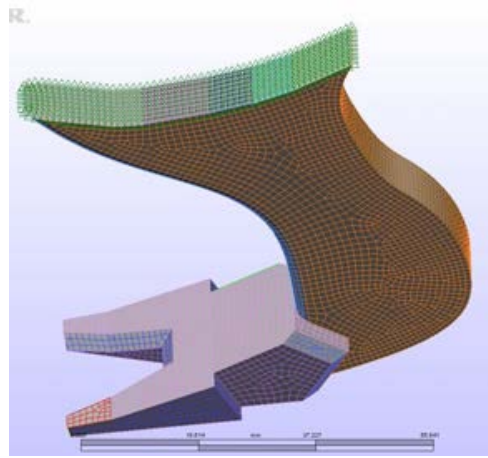

Fig. 9 The defining of the support set in the case of vertical solicitation

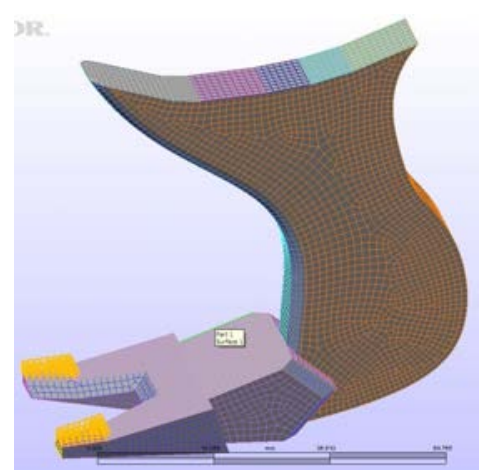

Fig. 10 The defining of the load set in the case of vertical solicitation

From the set of results obtained, it is interesting to visualize the stress state that occurs in the tooth and the displacement of its nodes under the action of the proposed solicitation.

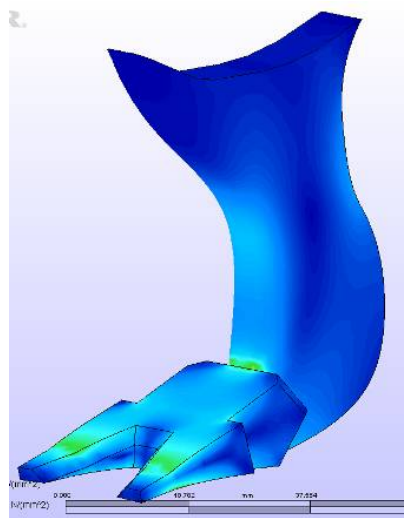

Fig. 11 The viewing of the the stress state in the case of vertical solicitation 


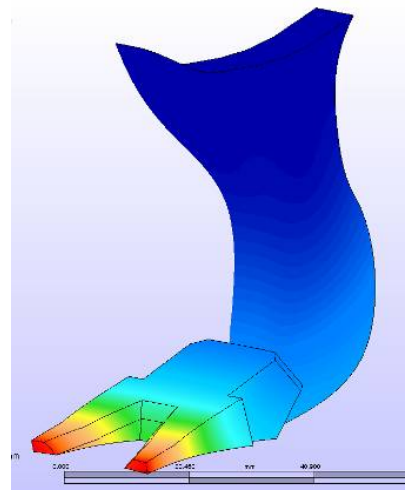

Fig. 12 The viewing of the displacements of the nodes from the tooth in the case of vertical solicitation

In a third state, it is proposed to overlap the two above-mentioned situations, considering the same type of support and load sets acting simultaneously. The finite element analysis leads to the following results:

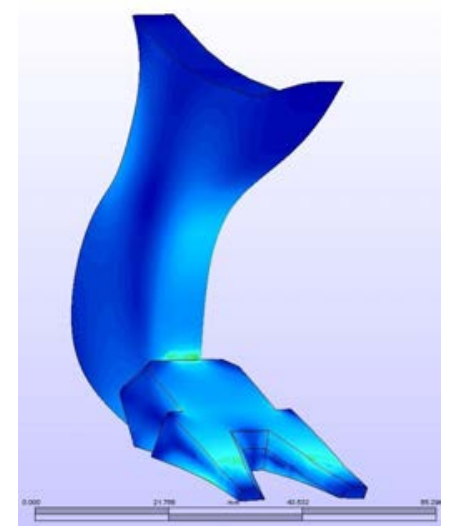

Fig. 13 The viewing of the stress state in the case of overlapping the previous load sets

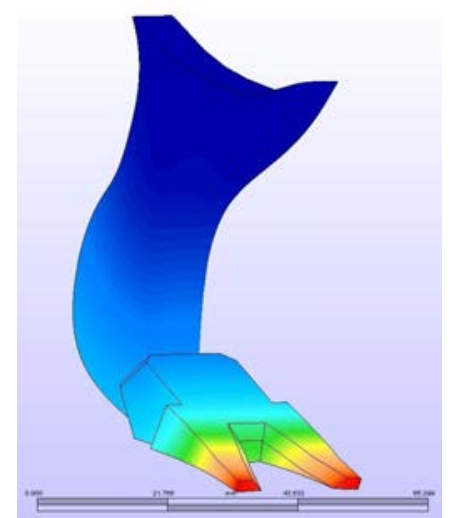

Fig. 14 The viewing of the displacements of the nodes from the tooth in the case of overlapping the previous load sets

\section{CONCLUSIONS}

The results provided by the finite element analysis software lead to the following conclusions:

- the values obtained for the stress state when the tooth is frontally solicited are the lowest; if the tooth is vertically solicited, the stresses are significantly higher and in the case of overlapping, the stresses values are the highest. However, the stress values obtained in all the cases presented are small compared to the admissible stress of the material, which leads to the conclusion that these stresses do not pose a danger to the tooth in the sense of making it crack to any of the solicitations or even to the two solicitations overlapped;

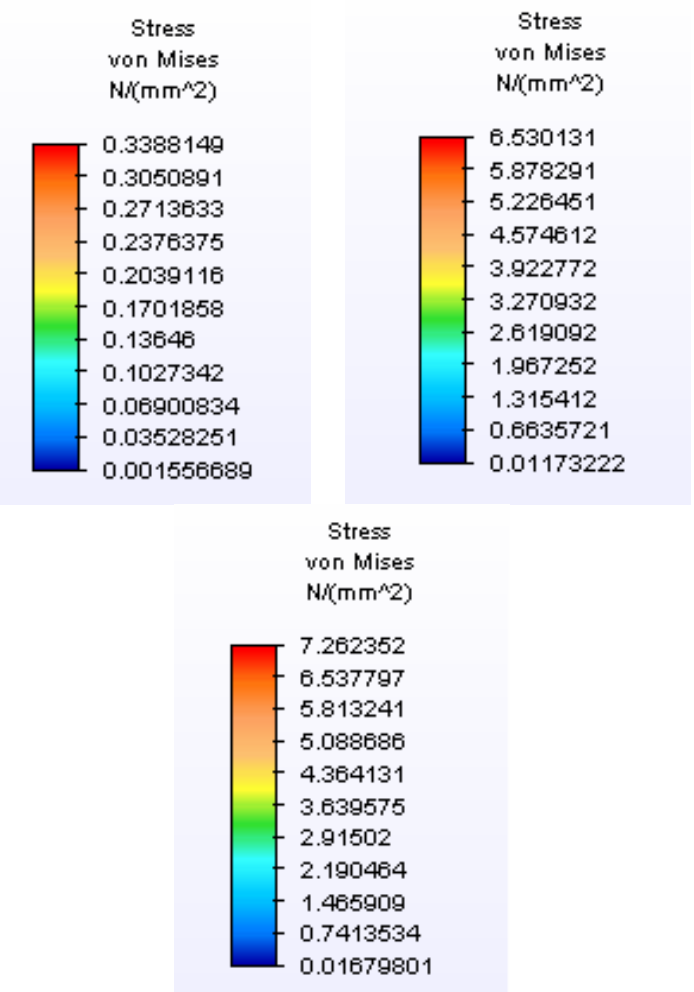

Fig. 15 The values obtained for stress in the three states of stress

- the values obtained for the displacements of the nodes of the tooth increase in the same time with the increasing of the tensions and in the same order in which the tensions increase;

- the present paper can be used as a starting point for equipment design specialists and can be continued to improve the geometric configuration and the working performance of such equipments. 
Displacement Magnitude

$\mathrm{mm}$

Displacement Magnitude

$\mathrm{mm}$

0.0001700472
0.0001530425
0.0001360378
0.0001190331
0.0001020283
$8.502361 \mathrm{e}-005$
$6.801889 \mathrm{e}-005$
$5.101417 \mathrm{e}-005$
$3.400944 \mathrm{e}-005$
$1.700472 \mathrm{e}-005$
0

0

\section{Displacement}

Magnitude

$\mathrm{mm}$

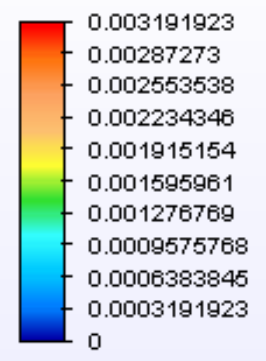

Fig. 16 The values for the displacements of the nodes of the tooth obtained in the three states of stress

\section{REFERENCES}

[1] Debeleac, C., Maşini și echipamente tehnologice pentru construcții, suport de curs în format electronic, Facultatea de Inginerie şi Agronomie din Brăila

[2] Dumitrache, P., Analiză cu elemente finite, suport de curs în format electronic, Facultatea de Inginerie şi Agronomie din Brăila, 2007

[3] Dumitrache, P., Optimizarea structurilor folosind metoda elementului finit, suport de curs în format electronic, Facultatea de Inginerie și Agronomie din Brăila, 2007

[4] Goanță, A.M., Infografică $2 D / 3 D$, ISBN 978-9739458-81-8, Editura LUX LIBRIS, Braşov, 2006

[5] Mihăilescu, Șt., Maş̧ini de construcții și pentru prelucrarea agregatelor, Editura Didactică și Pedagogică, Bucureşti, 1983

[6] https://whtequipments.com/pcat/atasamenteexcavator/

[7] https://www. scribd.com/document/264503663/Masi ni-si-utilaje-de-constructie-I-Curs-6-7-8Excavatoare

[8] https://www.plm.automation. siemens.com/en/produ cts/solid-edge/ 